\title{
Unsur-Unsur Sejarah dan Nilai Pendidikan Karakter dalam Kumpulan Cerpen Teh dan Pengkhianat Karya Iksaka Banu
}

\author{
Tita Oktiva ${ }^{1)}$ \\ Universitas Indraprasta PGRI \\ Jalan Nangka No. 58 C/TB. Simatupang, Tanjung Barat, Jakarta Selatan 12530 \\ Oom Rohmah Syamsudin ${ }^{2)}$ \\ Universitas Indraprasta PGRI \\ Jalan Nangka No. 58 C/TB. Simatupang, Tanjung Barat, Jakarta Selatan 12530 \\ titaoktiva@gmail.com ${ }^{1)}$,orsyamsudin@gmail.com ${ }^{2)}$
}

\begin{abstract}
The purpose of this study was to describe the historical elements and the value of character education in a the collections of short stories "Teh dan Pengkhianat" by Iksaka Banu. The research method used by researchers in analyzed this collection of short stories is descriptive method with structuralism approach. Data collection techniques used in this research are reading and note-taking. The results of the study were concluded: 1) Elements of history displayed in the collction of short stories "Teh dan Pengkhianat" by Iksaka Banu grouped into three, namely historical events 67\%, historical figures $20 \%$ and historical time 13\%. 2) The value of character education displayed in the collection of short stories "Teh dan Pengkhianat" by Iksaka Banu contains 13 types of character education values with a total 25 data.
\end{abstract}

Keywords: Historical elements, Educational value, Teh dan Pengkhianat

\begin{abstract}
Abstrak
Tujuan penelitian ini untuk mendeskripsikan unsur-unsur sejarah dan nilai pendidikan karakter dalam kumpulan cerpen "Teh dan Pengkhianat" karya Iksaka Banu. Metodologi penelitian yang digunakan untuk menganalisis kumpulan cerpen ini adalah metode deskriptif dengan pendekatan struktural. Teknik pengumpulan data yang digunakan adalah teknik baca dan catat. Hasil penelitian disimpulkan: 1) Unsur sejarah yang ditampilkan dalam kumpulan cerpen "Teh dan Pengkhianat" karya Iksaka Banu dikelompokkan menjadi tiga, yaitu peritiwa sejarah 67\%, tokoh sejarah $20 \%$ dan waktu sejarah $13 \%$. 2) Nilai pendidikan karakter yang ditampilkan dalam kumpulan cerpen "Teh dan Pengkhianat" karya Iksaka Banu terdapat 13 jenis nilai pendidikan karakter dengan jumlah data 25.
\end{abstract}

Kata Kunci: Unsur-unsur sejarah, Nilai Pendidikan Karakter, Teh dan Pengkhianat

\section{PENDAHULUAN}

Karya sastra merupakan bentuk cerminan atau gambaran kehidupan masyarakat dengan bahasa sebagai media penyampaiannya. Karya sastra terlahir dari kreativitas pengarang dalam menuangkan ide. Kreativitas pengarang yang dapat dijadikan inspirasi dalam berkarya dapat berupa peristiwa yang pernah terjadi seperti sejarah. Sastra dan sejarah memiliki hubungan yang saling 
berkaitan. Sejarah dapat dijadikan sumber sastra dan sastra dapat dijadikan media untuk menggambarkan sejarah.

Karya sastra yang mengandung unsur sejarah berangkat dari realitas sosial yang secara nyata pernah terjadi dan dikombinasikan dengan nilai estetis. Bentukbentuk realitas sosial budaya tersebut mengandung nilai ilmiah sehingga karya sastra yang mengangkat realitas ilmiah disebut fiksi sejarah.

Sebuah karya fiksi sejarah memiliki bahan baku realitas sejarah. Jika realitas itu berupa peristiwa sejarah, maka menurut Kuntowijoyo (1987: 127) terdapat tiga alasan: pertama, mencoba menerjemahkan peristiwa itu ke dalam bahasa imajiner dengan maksud untuk memahami peristiwa sejarah menurut kadar kemampuan pengarang; kedua karya sastra dapat menjadi sarana bagi pengarangnya untuk menyampaikan pikiran, perasaan, dan tanggapan mengenai suatu peristiwa sejarah; dan ketiga, karya sastra dapat merupakan penciptaan kembali sebuah peristiwa sejarah sesuai dengan pengetahuan dan daya imajinasi pengarang.

Karya sastra yang mengandung unsur sejarah terdapat dalam kumpulan cerpen Teh dan Pengkhianat karya Iksaka Banu yang mendapatkan penghargaan Kusala Sastra Khatulistiwa 2019 pada kategori prosa. Kumpulan cerpen ini terdiri dari 13 cerita pendek, yang pada umumnya menceritakan peristiwa-peristiwa yang pernah terjadi sesuai dengan peristiwa sejarah di Indonesia. Peristiwa sejarah digambarkan di setiap cerpen, mulai dari kedatangan Belanda ke Indonesia yang ingin menguasai perdagangan di Banda, peperangan pada masa penjajahan, perjuangan kemerdekaan bangsa Indonesia, hingga pemulangan bangsa Belanda pascakemerdekaan.

Sejarah dalam cerpen ini digambarkan lewat latar di setiap cerpen. Sebagaimana menurut Ratna (2007: 348) bahwa hubungan karya sastra terhadap sejarah adalah unsur sastra dapat berupa cerita, tokoh, dan latar yang esensial mengandung unsur sejarah. Meskipun sastra bersifat imajinatif tetapi selalu berangkat dari kenyataan. Ada tiga masalah yang perlu dikemukakan dengan relevansi sejarah terhadap sastra, yaitu: 1) relevansi fakta-fakta sejarah, dalam hal ini berkaitan dengan isi, 2) homologi unsur-unsur dalam hal ini berkaitan dengan struktur, 3) relevansi proses kreatif dalam hal ini berkaitan dengan perkembangan genre sastra.

Selain latar, semua tokoh utama yang ditampilkan adalah orang berkulit putih. Konflik yang ditampilkan pun adalah perjuangan para tokoh dalam menentang ideologi bangsanya sendiri melalui berbagai peristiwa sejarah. Relevansi latar dan peristiwa yang ada dalam cerpen ini berkaitan dengan fakta sejarah yang terjadi di Indonesia, yaitu kolonialisme Belanda terhadap Indonesia.

Melalui kumpulan cerpen ini, Iksaka Banu meramu sejarah dengan cara yang berbeda. Sejarah yang selama ini dikenal sangat membosankan diubah menjadi penuh warna melalui karyanya. Sebagaimana Iksaka Banu menyebutkan dalam pengantar buku kumpulan cerpen Teh dan Pengkhianat, "Saya menulis fiksi sejarah adalah menjadi jembatan kecil, titik perkenalan awal bagi generasi muda agar tertarik membaca sejarah negeri kita yang sungguh kaya dan penuh warna dalam wujud buku sejarah aslinya kelak". 
Penulis menemukan bahwa pengarang menyajikan berbagai peristiwa bersejarah dengan sudut pandang yang berbeda dengan mengangkat semua tokoh utama adalah orang berkulit putih yang merupakan bagian dari bangsa yang menjajah Indonesia. Pengarang seolah ingin memperlihatkan kepada pembaca bahwa tidak semua penjajah tidak memiliki nurani tetapi semua tokoh dalam cerpen ini berjuang melawan ideologi bangsa Belanda pada umumnya dan berpihak pada Indonesia atas dasar agama dan kemanusiaan serta menjaga martabat bangsa Eropa di mata dunia.

Hal menarik yang bisa dipelajari dari kumpulan cerpen Teh dan Pengkhianat adalah unsur sejarah yang ditampilkan dalam setiap peristiwa bisa digunakan sebagai pembentuk karakter siswa dalam pembelajaran sastra. Pendidikan karakter dalam sebuah karya sastra dapat mempengaruhi perkembangan sikap positif pada diri seseorang. Nurhayati dalam Wibowo (2013: 19) menyebutkan bahwa pengajaran sastra memiliki pertautan erat dengan pendidikan karakter, karena pengajaran sastra dan sastra pada umumnya, secara hakiki membicarakan nilai hidup dan kehidupan yang mau tidak mau berkaitan langsung dengan pendidikan karakter manusia. Sastra dalam pendidikan anak bisa berperan mengembangkan aspek kognitif, afektif, psikomotorik, mengembangkan kepribadian dan mengembangkan pribadi sosial.

Kandungan unsur sejarah dan nilai pendidikan karakter yang terdapat dalam kumpulan cerpen Teh dan Pengkhianat karya Iksaka Banu menjadikan penulis tertarik untuk mengkaji secara komprehensif bagaimana unsur-unsur sejarah dan pendidikan karakter dalam kumpulan cerpen Teh dan Pengkhianat karya Iksaka Banu dipahami oleh pembaca dan dapat dijadikan sebagai acuan dalam pendidikan karakter bagi genersi bangsa Indonesia.

\section{METODE}

Metode yang digunakan dalam penelitian ini adalah metode deskriptif. Menurut Ratna (2011: 44) metode deskriptif, hermeneutika, atau metode analisis isi, yaitu suatu metode dengan cara kerja memberikan interpretasi, pemahaman terhadap objek yang diamati.

Metode deskriptif dipilih karena penelitian ini berusaha mendeskripsikan dan menginterpretasi struktur yang terkandung dalam kumpulan cerpen Teh dan Pengkhianat karya Iksaka Banu. Deskripsi dan analisis dilakukan terhadap struktur pembangun sebuah cerpen yaitu, alur, tokoh dan penokohan, latar, tema, dan sudut pandang. Struktur pembangun cerpen tersebut penulis gunakan untuk mendeskripsikan unsur-unsur sejarah dan nilai pendidikan karakter kumpulan cerpen Teh dan Pengkhianat karya Iksaka Banu.

Dalam penelitian ini yang menjadi data adalah karya sastra dalam bentuk kumpulan cerpen yang terdiri dari 13 cerpen. Untuk melaksanakan teknik penelitian digunakan instrumen sebagai berikut: 1) indikator analisis unsur data instrinsik, 2) indikator analisis intertekstualitas, 3) indikator analisis nilai pendidikan karakter. Teknik pengumpulan data yang digunakan adalah teknik baca dan catat 
Teknik analisis data dalam penelitian ini (Mukhtar, 2013: 135), antara lain: 1) Reduksi data (data reduction), penulis memilih dan memilah-milah data yang akan dianalisis berupa kata, kalimat, atau ungkapan yang menyangkut tentang isi cerita dalam bentuk sekuen. 2) Sajian data (data display), penulis menampilkan data-data yang telah dipilih dan dipilah-pilah dan menganalisis unsur sejarah dan nilai pendidikan karakter; 3) Verification, penulis menyimpulkan hasil analisis mengenai unsur sejarah dan nilai pendidikan karakter.

\section{HASIL DAN PEMBAHASAN}

\section{Hasil}

Temuan penelitian ini diawali dengan mendeskripsikan cerita dengan struktur isi. Melalui kajian struktural diperoleh unsur intrinsik setiap cerpen. Tujuan dari kajian struktural ini untuk menangkap makna secara menyeluruh setiap cerpen, sehingga dapat ditemukan unsur-unsur sejarah dan nilai pendidikan karakter yang terdapat dalam kumpulan cerpen Teh dan Pengkhianat.

Tabel 1. Data Unsur Sejarah

\begin{tabular}{lllll}
\hline \multirow{2}{*}{ Unsur Sejarah } & $\begin{array}{l}\text { Peristiwa } \\
\text { Sejarah }\end{array}$ & $\begin{array}{l}\text { Tokoh } \\
\text { Sejarah }\end{array}$ & Waktu Sejarah & Jumlah \\
\cline { 2 - 5 } & 10 & 3 & 2 & 15 \\
\hline Presentase & $67 \%$ & $20 \%$ & $13 \%$ & $100 \%$ \\
\hline
\end{tabular}

Tabel 2. Data Nilai Pendidikan Karakter

\begin{tabular}{cll}
\hline No & Nilai Pendidikan Karakter & Jumlah \\
\hline 1 & Religius & 2 \\
2 & Jujur & 2 \\
3 & Toleransi & 2 \\
4 & Kerja & 2 \\
5 & Kreatif & 1 \\
6 & Demokratis & 2 \\
7 & Rasa ingin tahu & 1 \\
8 & Cinta tanah air & 1 \\
9 & Menghargai prestasi & 2 \\
10 & Cinta damai & 1 \\
11 & Gemar membaca & 1 \\
12 & Peduli sosial & 5 \\
13 & Tanggung jawab & 3 \\
\hline
\end{tabular}




\section{Pembahasan}

Berdasarkan deskripsi data temuan penelitian tersebut, berikut unsur-unsur sejarah dan nilai pendidikan karakter yang terdapat dalam kumpulan cerpen Teh dan Pengkhianat karya Iksaka Banu.

Unsur-unsur sejarah yang ditemukan dikelompokkan menjadi tiga, yaitu:

\section{Peristiwa Sejarah}

Peristiwa sejarah yang terdapat dalam kumpulan cerpen "Teh dan Pengkhianat" karya Iksaka Banu terdapat 10 peristiwa dalam cerpen yang berbeda. Peristiwa sejarah yang terdapat dalam setiap cerpen dijadikan pengarang sebagai latar cerita. Berikut 10 peristiwa sejarah tersebut:

1) Peristiwa pembantaian di pantai Naira yang terdapat dalam cerpen Kalabaka. "Aku harus jujur padamu, Driek," katanya. "Kemungkinan besar kita akan langsung menghadapi beberapa pertempuran brutal di Banda. Ada dendam Tuan Coen terkait kegagalan misi VOC terdahulu yang ingin ia lampiaskan." (Banu, hal. 5)

Kutipan di atas menunjukkan bahwa kegagalan Tuan Coen dalam misi VOC terdahulu menjadi motif dalam pembantaian di pantai Naira yang sekaligus menjadi latar cerpen Kalabaka.

2) Peristiwa Pemberontakan Cina di Tanjungpura terdapat dalam cerpen Teh dan Pengkhianat.

"Kelompok Cina Wanayasa bergerak tanggal 10 Mei kemarin, melintasi perkebunan teh menuju Sindangkasih dari arah selatan." (Banu, hal. 35)

Kutipan di atas menggambarkan peristiwa pemberontakan kelompok Cina Wanayasa sebagai bentuk protes terhadap Belanda yang berbuat licik terhadap para buruh Cina.

3) Peristiwa pembakaran ladang tebu di Jawa Timur terdapat dalam cerpen Sebutir Peluru Saja.

"Aku dan teman-temanku dulu petani biasa. Tetapi makelar haus darah macam Bendoro dan kawan-kawannya itu membuat kami tak punya lagi sawah untuk digarap. Semua ladang ditanami tebu, dan tidak pernah dikembalikan. (Banu, hal. 62)

Kutipan di atas menunjukkan bahwa protes yang dilakukan Kalasrengi mewakili cerita para petani yang kecewa dengan pemerintah karena ladang mereka ditanami tebu dan warga dipaksa untuk menjadi buruh dengan upah yang tidak sesuai sehingga marak terjadi pembakaran ladang tebu sebagai bentuk protes.

4) Wabah kolera dalam pertempuran Aceh terdapat dalam latar cerpen Lazarus tak Ada di Sini.

"Aku membayangkan kepanikan mereka saat melihat Jenderal Kohler tewas tertembak beberapa tahun yang lalu. Tetapi pembunuhan terbesar di medan prang yang basah ini sesungguhnya bukan peluru atau kelewang, melainkan wabah kolera. Pihak Aceh pun banyak yang dimangsa penyakit mengerikan ini. Termasuk Sultan Mahmud Syah.” (Banu, 69) 
Kutipan di atas menunjukkan wabah kolera pada masa peperangan Aceh adalah latar suasana dalam cerpen.

5) Penerapan sistem regie opium terdapat dalam cerpen Kutukan Lara Ireng.

"Begitulah. Tuan Mechelen ingin agar pemerintah berhenti mengimpor opium mentah, dan mulai memproduksi serta mengolah sendiri opium secara besarbesaran di Hindia. (Banu, hal. 83)

Kutipan di atas menunjukkan penjelasan sistem regie. Sistem regie ini menjadi latar sosial cerpen ini.

6) Kebangkitan bumi putra dalam memperoleh keadilan terdapat dalam latar cerpen Kereta Angin.

"Kaitannya, perubahan ini memberi inspirasi kepada para bumiputra untuk mencari keadilan dan kesetaraan serupa. Terutama setelah perkumpulan Budi Utomo dan Sarikat Dagang Islam berdiri." (Banu, hal. 97)

Kutipan di atas menunjukkan bahwa Setelah Boedi Oetomo dan Sarikat Dagang berdiri bumiputra mulai memperoleh keadilan dan kesetaraan, yaitu mendirikan sekolah khusus bumiputra, berbusana Eropa dan boleh mengendarai sepeda.

7) Eksistensi Redaksi Bataviaasch Niewsblad terdapat dalam latar cerpen Nieke de Flinder.

"Apakah engkau masih Abraham de Withart seperti yang kutemui d Bataviasch Nieuwsblad?" sambungnya. Aku menghela nafas, "Spiegel belum segila Bataviasch Nieuwsblad. (Banu, hal. 122)

Pernyataan Abraham ini menunjukkan bahwa Bataviaasch Nieuwsblad adalah redaksi yang berani bicara kebenaran. Redaksi ini koran berbahasa Belanda yang menjadi corong suara orang-orang Indonesia Belanda.

8) Pertempuran Rancamanggung terdapat dalam cerpen Tawanan

Upaya diplomasi tidak membuahkan hasil, dan kontak senjata yang meletus pada pukul 05.00 pagi berhasil membuat para ekstremis itu surut ke arah Rancamangung. (Banu, hal. 130)

Kutipan di atas menunjukkan kontak senjata yang berhasil memukul mundur TNI ke Rancamanggung.

9) Solidaritas buruh Australia mendukung kemerdekaan RI terdapat dalam latar cerpen Indonesia Memanggil.

Aku terus mengayun langkah. Di ujung antrean, kulihat sebuah pawai panjang, terdiri dari ratusan buruh Autralia berkulit putih, dan sejumlah orang berkulit coklat. Mereka bernyanyi lagu mars sambil membawa spanduk dan plakat. (Banu, hal. 164)

Kutipan di atas menunjukkan bahwa para buruh melakukan aksi sebagai bentuk solidaritas untuk mendukung kemerdekaan bangsa Indonesia.

10) Repatriasi Belanda terdapat dalam cerpen Semua Sudah Selesai

Lalu memberi ultimatum agar semua orang Belanda secepatnya meninggalkan Indonesia, atau mengubah status kewarganegaraan, bergabung dengan Indonesia. (Banu, hal.169)

Kutipan di atas menunjukkan bahwa Sukarno memberi ultimatum tentang repratiasi orang Belanda. 


\section{Tokoh Sejarah}

Tokoh sejarah dalam cerpen ini terdapat tiga tokoh yaitu:

1) Karaeng pattingaloang terdapat dalam cerpen Tegak Dunia

"Pemesannya adalah Karaeng Pattingaloang, Mangkubumi dari kerajaan Gowa, seorang bumiputra!” (Banu, hal. 28)

Tokoh Karaeng sebagai seorang bumiputra yang takzim pada ilmu Eropa.

2) Ali Basah Sentot Prawirodirjo terdapat dalam cerpen Teh dan Pengkhianat "Namanya, Alibasah Sentot Prawirodirjo. Ia tangan kanan Diponegoro. Kemampuan tempur dan penguasaan strategi lapangannya sangat tinggi." (Banu, hal. 39)

Ali Basah dalam cerpen ini sebagai pemimpin pasukan dari Batavia untuk meredam kerusuhan di Tanjungpura.

3) Roehana Koeddoes terdapat dalam cerpen Belenggu Emas

"Lihat, yang kau tunggu sudah datang. Pendiri sekolah Amai Setia dan pemilik surat kabar Soenting Melajoe." (Banu, hal. 116)

Sesuai dengan sejarah, Roehana dalam cerpen adalah pendiri sekolah Amai Setia dan pemilik surat kabar Soenting Melajoe. Roehana menjadi tokoh yang menginspirasi perempuan Belanda untuk bebas dari belenggu suaminya.

\section{Waktu Sejarah}

Waktu sejarah dalam kumpulan cerpen ini terdapat dua, yaitu pada tahun 1621 dalam cerpen Kalabaka dan tahun 1871 terdapat dalam latar cerpen Variola yang dijelaskan sebagai penyebaran wabah cacar terparah di Bali yang menyebabkan delapan belas ribu kehilangan nyawa.

Berikut merupakan nilai-nilai pendidikan karakter dalam kumpulan cerpen Teh dan Pengkhianat:

\section{Religius}

Nilai religius terdapat dalam cerpen Lazarus tak Ada di Sini Pada tokoh Van Knecth dan Letnan Lazarus Willem Stijfhart.

Tugas utamaku menjadi pelipur dan penguat tentara Hindia Belanda. Tetapi aku juga seorang pengabdi kemanusiaan. (Banu, hal. 69)

Tugas pelipur dan penguat tentara Hindia Belanda menunjukkan karakter religius dari tokoh Van Knecth dalam menjalankan tugasnya sebagai pastor.

\section{Jujur}

Karakter jujur terdapat dalam cerpen Nieke de Flinder pada tokoh Abraham. Tokoh Abraham de Withart adalah seorang redaktur pelaksana di kantor Redaksi Spiegel van Insulande lebih memilih mengundurkan diri demi menegakkan kebenaran dalam memuat berita.

Siang itu, aku menulis dua buah surat. Surat pertama, adalah permohonan pengunduran diriku dari Siegel van Insulinde. Surat kedua, kualamatkan pada Karel Zaalberg, pemimpin redaksi Bataviaasch Nieuwsblad. (Banu, hal. 124)

Kutipan di atas menunjukkan bahwa Abraham memilih keluar dari Spiegel demi menerbitkan berita yang memuat kebenaran. Karakter jujur juga terdapat dalam cerpen Indonesia Memanggil pada penokohan Letnan Marteen. 


\section{Toleransi}

Karakter toleransi terdapat pada tokoh Kapten Van de Vlek dalam cerpen Tegak Dunia. Karakter toleransi Kapten dalam cerpen, yaitu menghargai pastor panti, Tuan Geloofig, yang berbeda pandangan mengenai bentuk bumi.

Sesungguhnya amarah kapten sudah tiba diujung tanduk, tetapi rasanya tak baik memaki seseorang yang dekat dengan Alkitab. (Banu, hal.26)

Kutipan di atas menunjukkan bahwa Kapten menghargai pendapat pastor, walaupun sebenarnya Kapten sangat marah. Selain tokoh Kapten, karakter toleransi ditemukan pula pada cerpen di Atas Kereta Angin pada penokohan Kees.

\section{Kerja keras}

Karakter kerja keras terdapat pada tokoh Benedict dalam cerpen Semua sudah Selesai. Karakter pekerja keras tokoh Benedict dijelaskan lewat tuturannya saat menjelaskan perjuangan meneruskan usaha warisan Papanya.

"Aku setengah mati meneruskan usaha ini dari almarhum Papa. (Banu, hal. 160)

Kutipan di atas menunjukkan bahwa Benedict berusaha keras yang ditunjukkan dengan kata 'setengah mati' dalam meneruskan usaha dari almarhum papanya hingga masih bisa berdiri sampai sekarang. Karakter kerja keras juga terdapat pada penokohan Kapten Van de Vlek dalam cerpen Tegak Dunia.

\section{Kreatif}

Karakter kreatif terdapat pada tokoh Nellie dalam cerpen Belenggu Emas. Belakangan, lewat sebuah keributan hebat, ia tidak lagi memperbolehkanku membeli koran walau masih boleh membeli buku. Kubalas perlakuannya dengan pindah tidur ke kamar lain. Kukunci pintu. Lalu kuhabiskan malam-malam panjang dengan menulis sajak atau karangan lain dalam berlembar kertas. (Banu, hal. 115)

Kutipan di atas menggambarkan tokoh Nellie hidup dalam belenggu emas suaminya sehingga ruang geraknya dibatasi. Ia memanfaatkan keterbatasannya dengan menghabiskan malam-malam panjangnya melalui menulis untuk menuangkan perasaannya.

\section{Demokratis}

Karakter demokratis terdapat pada tokoh Kapten Simon Vastgebonden dalam cerpen Teh dan Pengkhianat.

"Aku juga tidak ingin berdebat. Pun tidak memihak kepada para pemberontak. Tugasku sekarang memadamkan api ini sedini mungkin. Aku hanya ingin mengatakan, cukup sering kekacauan bermula dari diri kita sendiri. Seandainya kita lebih bijaksana, hal seperti ini tidak akan terjadi. (Banu, hal. 36-37)

Kutipan di atas menunjukkan bahwa karakter demokratis Kapten adalah tidak memihak kepada Belanda, yang merupakan bangsanya sendiri dan ia juga tidak memihak kepada Cina. Kapten menyimpulkan duduk permasalahan berasarkan fakta di lapangan. Karakter demokratis juga terdapat pada tokoh Kees dalam cerpen di Atas Kereta Angin. 


\section{Rasa Ingin Tahu}

Karakter rasa ingin tahu terdapat pada tokoh Bernard Eigensteen yang biasa disapa Ben dalam cerpen Kutukan Lara Ireng.

"Mungkinkah para penyelundup opium itu sudah jera masuk pantai Jepara karena kau hajar habis-habisan selama ini?" (Banu, hal.76)

Kutipan di atas menunjukkan ras ingin tahu Ben terhadap para penyelundup opium yang tak kunjung ia temui. Ben menanyakan kepada Kapten kemungkinan jera para penyelundup opium gelap.

\section{Cinta Tanah Air}

Karakter cinta tanah air terdapat pada tokoh Hendriek Cornelis Adam dalam cerpen Kalabaka. Karakter cinta tanah air tergambar dalam sikapnya yang menjunjung peradaban tinggi Eropa, bangsanya sendiri.

Kini ia terpuruk di sini, setengah telanjang. Menghadapi maut dengan cara mengerikan di tangan orang Eropa yang mengaku memiliki peradaban tinggi. Alangkah anehnya hidup ini. (Banu, hal. 15)

Kutipan di atas menunjukkan bahwa Hendriek menjunjung tinggi falsafah hidup orang Eropa sehingga ia menolak keras pelaksanaan hukuman yang biadab dan tidak berperikemanusiaan

\section{Menghargai Prestasi}

Tokoh yang memiliki karakter menghargai prestasi adalah Kapten Simon Vastgebonden dalam cerpen Teh dan Pengkhianat. Kapten mengakui kehebatan Sentot dan memuji pekerjaan Sentot. Ia berhasil mengesampingkan rasa bencinya terhadap Sentot.

"Kerja bagus, Tuan Sentot! Sangat bagus!" sahutku dalam bahasa Melayu searaya mengendurkan tekanan pada pelatuk senapan. Banu, (hal. 43)

Kutipan di atas menunjukkan bahwa rasa benci dan curiga kapten luluh setelah melihat bahwa Sentot profesional dalam menjalankan tugas sehingga ia pun mengakui kehebatan Sentot dan memujinya secara langsung. Karakter menghargai prestasi juga terdapat juga terdapat dalam cerpen Indonesia Memanggil pada penokohan Letnan Marteen

\section{Cinta Damai}

Tokoh yang memiliki karakter cinta damai adalah Kapten Van Oijen, yang biasa disapa Kapten Jan dalam cerpen Tawanan. Kapten meyakinkan tokoh aku agar membiarkan Indonesia merdeka sebagaimana negaranya yang ingin merdeka dari Nazi Jerman.

"Faktanya, penduduk tak ingin Belanda tinggal di sini. Sama seperti kita menolak Nazi Jerman bercokol lebih lama di negeri kita. (Banu, hal. 137)

Kutipan di atas menunjukkan bahwa Kapten menginginkan agar tokoh aku menyudahi peperangan dan membiarkan Indonesia merdeka sebagimana Belanda yang ingin lepas dari pendudukan Nazi Jerman. 


\section{Gemar Membaca}

Tokoh yang memiliki karakter gemar membaca adalah Nellie dalam cerpen Belenggu Emas. Karakter gemar membaca dapat dilihat dari kesukaan Nellie yang sering membaca karya sastra.

Setelah membaca, ada semacam panggilan untuk memperbaiki keadaan di sana. Seperti yang dikatakan Rudyard Kipling dalam salah satu sajaknya...."

Kutipan di atas menunjukkan bahwa Nellie gemar membaca karya sastra. Menurutnya, setelah membaca, ada semacam panggilan untuk memperbaiki keadaan di sana

\section{Peduli Sosial}

Tokoh yang memiliki karakter peduli sosial dalam kumpulan cerpen ini ada lima, yaitu Hendriek Cornelis Adam dalam cerpen Kalabaka, Tuan Adrian Geest dan Hendriek Plathart dalam cerpen Variola, Bernard Eigensteen dalam cerpen Kutukan Lara Ireng, dan Grijsman dalam cerpen Indonesia Memanggil. Berikut kutipan yang menunjukkan peduli sosial Tuan Adrian:

Kubenamkan tubuh di bangku dokar. Bergidik membayangkan amukan wabah cacar ke seluruh wilayah Hindia. Berapa banyak lagi umat manusia yang akan tumpas? (Banu, hal. 45)

Kutipan di atas menunjukkan kepedulian Tuan Adrian yang begitu besar terhadap penyebaran wabah variola sehingga ia sangat mengkhawatirkan nasib manusia jika donor belum didapatkan.

\section{Taanggung Jawab}

Tokoh yang memiliki karakter tanggung jawab adalah Kapten Zwarte Van de Vlek dalam cerpen Tegak Dunia, Tuan Skaut dalam cerpen Sebutir Peluru Saja, dan Benedict dalam cerpen Semua Sudah Selesai.

Tuan Skaut dalam cerpen Sebutir Peluru Saja digambarkan sebagai tokoh yang bertanggung jawab dalam menjalankan tugas. Sikap tanggung jawab Tuan Skaut dapat dilihat dari keputusannya memilih memenuhi permintaan mantri polisi yang meminta tolong kepadanya dan menunda rencana yang sudah ia susun demi perbaikan gajinya. Ia telah berhasil menghentikan kerusuhan meskipun telah melanggar prinsip hidupnya.

Ia masih berdiri termenung, mengamati asap yang mulai lenyap dari ujung bedilnya. Apakah tadi ia terkejut, lalu menarik pelatuk? Ataukah ia memang sengaja melakukan hal itu karena tak ingin dianggap sebagai pejabat bodoh yang begitu mudah ditipu seorang garong? Entahlah. Yang jelas kini ia harus memutar otak, menyusun alasan 'pembunuhan' yang masuk akal untuk dibuat menjadi laporan. (Banu, hal. 63)

Kutipan di atas menunjukkan bahwa Tuan Skaut tidak menyadari telah menembak Kalasrengi. Ia tetap bertanggung jawab atas apa yang terjadi hari itu. Sikap tanggung jawab Tuan Skaut ditandai dengan ia harus memutar otak menyusun alasan Kalasrengi sebagai peristiwa pembunuhan yang masuk akal. 


\section{SIMPULAN}

Berdasarkan hasil analisis unsur-unsur sejarah dan nilai pendidikan karakter dalam kumpulan cerpen "Teh dan Pengkhianat" karya Iksaka Banu, maka dapat ditarik simpulan bahawa unsur sejarah yang ditampilkan dalam kumpulan cerpen "Teh dan Pengkhianat" karya Iksaka Banu dikelompokkan menjadi tiga, yaitu peritiwa sejarah 67\%, tokoh sejarah $20 \%$ dan waktu sejarah $13 \%$. Nilai pendidikan karakter yang ditampilkan dalam kumpulan cerpen "Teh dan Pengkhianat" karya Iksaka Banu terdapat 13 jenis nilai pendidikan karakter dengan jumlah data 25

\section{DAFTAR PUSTAKA}

Banu, I. (2020). Teh dan pengkhianat. Jakarta: KPG (Kepustakaan Populer Gramedia

Kuntowijoyo, B. (1987). Budaya masyarakat. Yogyakarta: Tiara Wacana.

Mukhtar, P. D. (2013). Metode praktis penelitian deskriptif kualitatif. Jakarta: GP Press Group.

Ratna, N. K. (2007). Estetika sastra dan budaya. Pustaka Pelajar.

Ratna, N. K. (2011). Antropologi sastra: Peranan unsur-unsur kebudayaan dalam proses kreatif. Pustaka Pelajar.

Wibowo, A. (2013). Pendidikan karakter berbasis sastra. Yogyakarta: Pustaka Pelajar. 